\title{
Outcomes of Surgical Treatment for Carcinoid Heart Disease: A Systematic Review and Meta-Analysis
}

\author{
Diana C. Jiminez \\ Thomas Jefferson University, diana.jimenez@students.jefferson.edu
}

Thomas J. O'Malley, MD

Thomas Jefferson University, thomas.o'malley2@jefferson.edu

Abhiraj Saxena

Thomas Jefferson University, abhiraj.saxena@students.jefferson.edu

Matthew P. Weber

Thomas Jefferson University, matthew.weber2@jefferson.edu

=814tis ThSSamulelfaditional works at: https://jdc.jefferson.edu/si_ctr_2023_phase1 Thomas Jefferson University, louis.samuels@jefferson.edu

Part of the Translational Medical Research Commons

\section{Let us know how access to this document benefits you}

\section{Recommended Citation}

Jiminez, Diana C.; O'Malley, MD, Thomas J.; Saxena, Abhiraj; Weber, Matthew P.; Samuels, Louis E.; Entwistle, John W.; Guy, T. Sloane; Massey, H. Todd; Morris, Rohinton; and Tchantchaleishvili, Vakhtang, "Outcomes of Surgical Treatment for Carcinoid Heart Disease: A Systematic Review and Meta-Analysis" (2021). Phase 1. Paper 76.

https://jdc.jefferson.edu/si_ctr_2023_phase1/76

This Article is brought to you for free and open access by the Jefferson Digital Commons. The Jefferson Digital Commons is a service of Thomas Jefferson University's Center for Teaching and Learning (CTL). The Commons is a showcase for Jefferson books and journals, peer-reviewed scholarly publications, unique historical collections from the University archives, and teaching tools. The Jefferson Digital Commons allows researchers and interested readers anywhere in the world to learn about and keep up to date with Jefferson scholarship. This article has been accepted for inclusion in Phase 1 by an authorized administrator of the Jefferson Digital Commons. For more information, please contact: JeffersonDigitalCommons@jefferson.edu. 


\section{Authors}

Diana C. Jiminez; Thomas J. O'Malley, MD; Abhiraj Saxena; Matthew P. Weber; Louis E. Samuels; John W.

Entwistle; T. Sloane Guy; H. Todd Massey; Rohinton Morris; and Vakhtang Tchantchaleishvili 


\section{Outcomes of Surgical Treatment for Carcinoid Heart Disease: A Systematic Review and Meta-Analysis}

Diana C. Jimenez, Thomas J. O’Malley, Abhiraj Saxena, Matthew P. Weber, Louis E. Samuels, John W. Entwistle, T. Sloane Guy, H. Todd Massey, Rohinton J. Morris, Vakhtang Tchantchaleishvili**

Division of Cardiac Surgery, Thomas Jefferson University, Philadelphia, PA 


\section{Introduction and Objective}

Carcinoid Heart Disease (CaHD) develops from vasoactive substances released by neuroendocrine tumors which can cause significant patient morbidity and mortality without surgical intervention. There are currently very few studies on the condition as the rarity of the condition has not allowed for any high-quality trials.

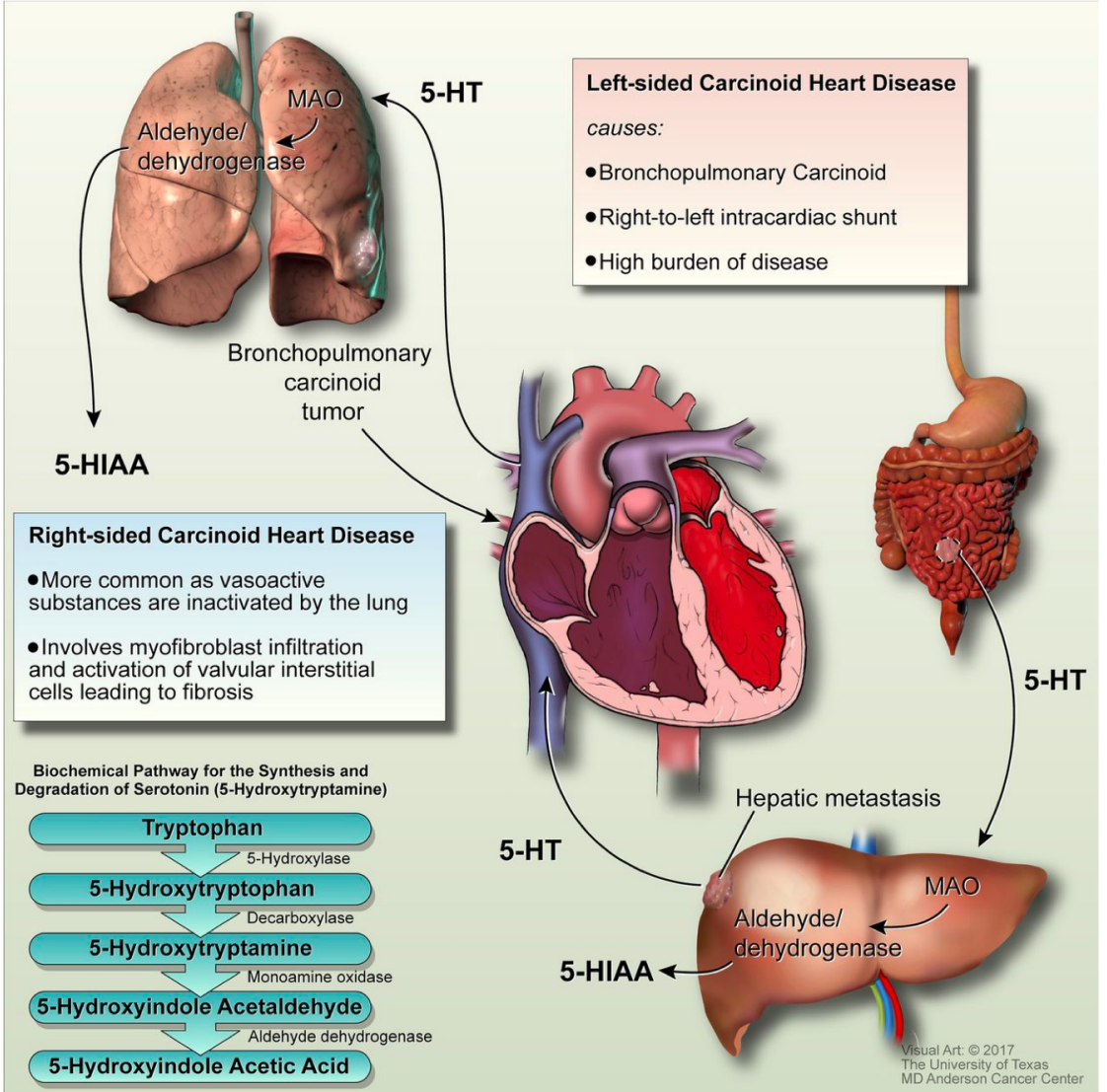




\section{Introduction and Objective}

We performed a systematic review and meta-analysis to elucidate granular perioperative details and long-term outcomes in these patients. This will allow for better understanding of the condition and provide guidance to clinicians when managing this rare disease. 


\section{Research Question \& Hypothesis}

Purpose: To investigate the safety and efficacy of valve replacement in patients with carcinoid heart disease

Question: Can valve replacement in patients with a neuroendocrine tumor (NE) and carcinoid heart disease (CaHD) be done safely and with acceptable long term outcomes? What are the peri-operative characteristics?

Hypothesis: Valve replacement in patients with an NE and CaHD can be done safely with acceptable outcomes. Valve replacement will mostly involve the tricuspid valve. 


\section{Approach and Results}

Study design: Meta-Analysis

Population: CaHD patients that receive Valvular surgery

- Intervention/Comparator: Not applicable

Outcome: Survival, Relief of CaHD Symptoms

Data source and collection: Systematic Search

Rationale: Meta-analysis was performed in order to aggregate the small number of studies in the literature to evaluate a rare condition with a large sample size

Electronic search of Ovid, Scopus, Cumulative Index of Nursing and Allied Health Literature, and Cochrane

Studies identified in databases $(n=620)$

Records after duplicates removed $(n=526)$

Records screened $(n=526)$

$\downarrow$

Articles assessed for eligibility $(n=18)$

$\downarrow$

Studies for qualitative synthesis $(n=9)$

Studies for quantitative synthesis $(n=9)$ Controlled Trials Register was performed to examine studies discussing surgical treatment of carcinoid disease. Nine articles comprising 416 patients were selected. Study-level data were extracted and pooled for meta-analysis. 


\section{Approach and Results}

\section{Analysis was performed using $\mathrm{R}$ software and included KM curve analysis along with other standard statistical analysis}

\section{Findings:}

Table 1: Baseline, Pre-operative, Peri-operative Characteristics and Outcomes of Patients Undergoing Valvular Surgery for Carcinoid Heart Disease

\begin{tabular}{|l|c|c|c|c|}
\hline \multicolumn{1}{|c|}{ Variables } & $\begin{array}{c}\text { Pooled Value } \\
{[95 \% \mathrm{Cl}]}\end{array}$ & No. of Studies & $\begin{array}{c}\text { No. of patients } \\
\text { (N or n/N) }\end{array}$ & $1^{2}$ (\%) \\
\hline Baseline Demographics & & & & \\
\hline Age (years) & $63[57 ; 70]$ & 8 & 377 & 0 \\
\hline Male (\%) & $53[46 ; 61]$ & 9 & $214 / 416$ & 39 \\
\hline BMI & $24.0[20 ; 28]$ & 3 & 291 & 0 \\
\hline Right Heart Failure Symptoms/Signs (\%) & $48[14 ; 81]$ & 4 & $36 / 88$ & $92^{*}$ \\
\hline Pre-Operative NYHA Class & & & & \\
\hline NYHA Class I (\%) & $2[0 ; 4]$ & 7 & $10 / 364$ & 0 \\
\hline NYHA Class II (\%) & $33[23 ; 43]$ & 6 & $97 / 345$ & 53 \\
\hline NYHAClass Ill \%) & $56[40 \cdot 72]$ & 6 & $183 / 347$ & $87^{*}$ \\
\hline NYHA Class IV (\%) & $48[10 ; 18]$ & 5 & $43 / 328$ & 0 \\
\hline Pre-operative Valve Dysfunction Characteristics & & & & $92^{*}$ \\
\hline Tricuspid Regurgitation, moderate or severe (\%) & $97[95 ; 99]$ & 7 & $367 / 377$ & 1 \\
\hline Pulmonary Regurgitation, moderate or severe (\%) & $72[58 ; 83]$ & 8 & $209 / 309$ & $75^{*}$ \\
\hline Pulmonary Stenosis, any, with or without regurgitation (\%) & $33[6 ; 60]$ & 5 & $33 / 113$ & $93^{*}$ \\
\hline Mitral Regurgitation, any (\%) & $24[0 ; 51]$ & 3 & $36 / 292$ & $94^{*}$ \\
\hline Aortic Regurgitation, any \%) & $18[1 ; 35]$ & 3 & $32 / 292$ & $86^{*}$ \\
\hline Peri-operative Characteristics & & & \\
\hline Valve Replacement with or without Additional Procedures & & & & \\
\hline Tricuspid Valve (\%) & $99[98 ; 100]$ & 9 & $407 / 416$ & 0 \\
\hline Bioprosthetic (\%) & $80[68 ; 93]$ & 9 & $344 / 416$ & $95^{*}$ \\
\hline Pulmonary Valve (\%) & $59[38 ; 79]$ & 9 & $244 / 416$ & $96^{*}$ \\
\hline Bioprosthetic (\%) & $59[23 ; 95]$ & 6 & $79 / 125$ & $98^{*}$ \\
\hline Mitral Valve (\%) & $8[5 ; 11]$ & 6 & $29 / 346$ & 0 \\
\hline Aortic Valve (\%) & $8[5 ; 11]$ & 7 & $30 / 360$ & 0 \\
\hline Outcomes & & & & \\
\hline Hospital Stay, days & $25[11 ; 39]$ & 5 & 103 & 0 \\
\hline 30 Day Mortality (\%) & $9[6 ; 12]$ & 9 & $43 / 416$ & 0 \\
\hline \hline Cause oj Veath & $20[11 ; 28]$ & 4 & $20 / 95$ & 0 \\
\hline Tumor Progression (\%) & $18[5 ; 30]$ & 4 & $15 / 88$ & 57 \\
\hline Sepsis/Pneumonia & $10[5 ; 14]$ & 6 & $16 / 144$ & 0 \\
\hline Cardiac Dysfunction (\%) & & & \\
\hline
\end{tabular}

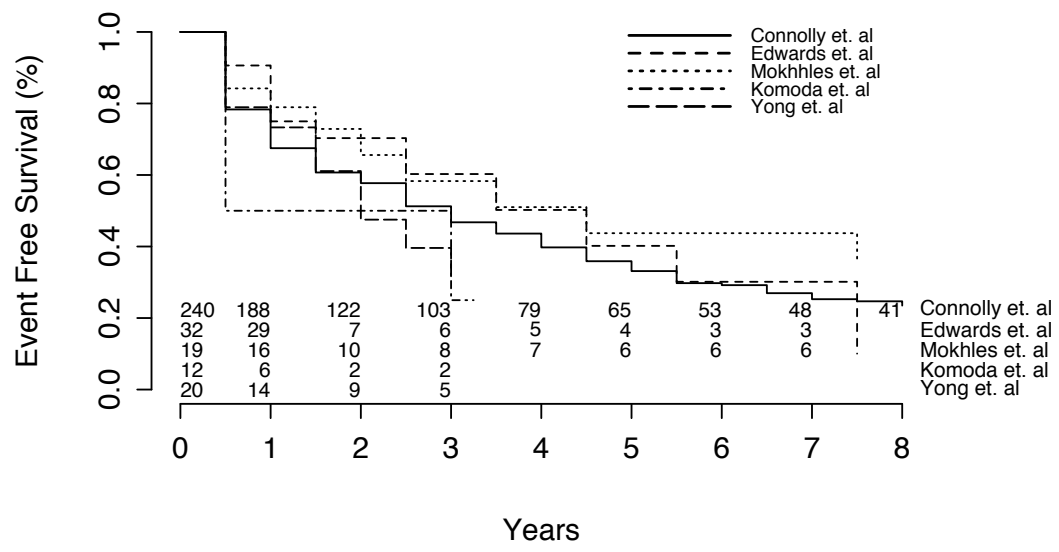




\section{Conclusions}

- Right heart failure was present preoperatively in $48 \%$ of patients

- Moderate to severe regurgitation was present in $97 \%$ of tricuspid and $72 \%$ of pulmonary valves

- Thirty-day mortality was $9 \%$ and median survival was 3 years

- Valve replacement in patients with a NET and CaHD be done safely with acceptable outcomes. Valve replacement mostly involved Pulmonary Valve Replacement in addition to Tricuspid Valve Replacement

- Mortality remains high, particularly at 5 and 10 years, primarily from progression of the primary disease

- Surgery was often delayed until NYHA III or IV Heart Failure and there is no consensus on how to monitor these patients, we suggest early referral to cardiology for close monitoring and early intervention 


\section{Future Directions}

- Future studies should investigate cardiac monitoring protocols for patients with Carcinoid Syndrome and the effects of operative timing on survival 


\section{Acknowledgments}

- Thank you to Dr. VT and Dr. Tommy O'Malley for all of their assistance and guidance with this project 


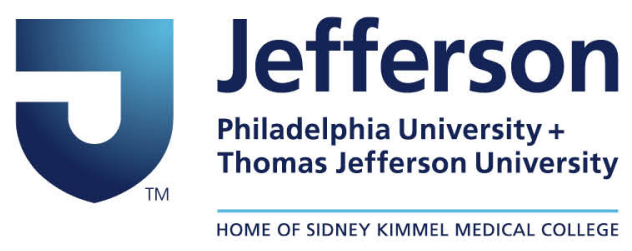

